\title{
Study of External Nest Appearances and Foraging Behavior of Tetragonula nr. pagdeni
}

\author{
Manjunatha Basanna ${ }^{1 *}$, Magdaline Christina Rajanand ${ }^{2}$
}

\author{
${ }^{1}$ Assistant Professor, Department of Zoology, Government Science College (Autonomous), Bengaluru, Karnataka, India \\ ${ }^{2}$ Student, Department of Post Graduate Studies in Zoology, Government Science College (Autonomous), Bengaluru, \\ Karnataka, India
}

*Address for Correspondence: Mr. Manjunatha Basanna, Assistant professor, Department of Zoology, Government Science College (Autonomous), Bengaluru Karnataka, India

E-mail: manjunatha.b01@gmail.com

Received: 26 Jun 2021/ Revised: 23 Aug 2021/ Accepted: 03 Oct 2021

\begin{abstract}
Background: The eusocial stingless bees (family Apidae: dammer bees) are found everywhere. They exhibit different nesting habits and also diverse habitat preferences. The nest entrance plays a very important role towards nest characters. The nest entrance prevents airstreams but allows slow gas exchange.

Methods: A study was conducted to elucidate data on the nesting sites, external nest characteristics, foraging behaviour at three selected study areas, pollen sources and identification and determination of the percentage of drone bees of $T \mathrm{nr}$. pagdeni at Bengaluru during the months of summer in the year 2019. The selected three study areas are Campus of the University of Agricultural Science (GKVK), Government Science College and DGQA Residential Complex (CQAL campus).

Results: Of the 28 stingless bee nests, twenty were found in stone walls at a mean height of $1537.7 \mathrm{~mm}$ from the ground. The entrance of the colony was either made of mud or a waxy dark coloured substance called resin. The most preferred substance used for building the entrance tube was found to be resin. The activity of foragers was observed from 7:00 hours to 17:00 hours at GKVK, Bengaluru. The highest activity was observed at 1100 hours ( 37.38 bees per 5 mins).

Conclusion: Study area has given the relevance of ecologically sustainable, economically viable scope as it interlinks the conservation of plant species for the continuity of the generations of stingless bees Knowledge of bee flora vis-à-vis bee diet is essential for sustainable meliponiculture, management, and proper conservation strategies for a sustainable livelihood in our region.
\end{abstract}

Key-words: Foraging, Stingless bee, Sustainable livelihood, Tetragonula

\section{INTRODUCTION}

The eusocial stingless bees (family Apidae: dammer bees) are found everywhere. Their size can range from 2 to $16 \mathrm{~mm}$. Tetragonula is a genus of stingless bees. There are more than 500 species worldwide ${ }^{[1,2]}$ and nine have been reported from India ${ }^{[3]}$. They are Lepidotrigona arcifera [4] Lisotrigona cacciae [5], L. mohandasi [6], Tetragonula aff. laeviceps (Smith), T. bengalensis ${ }^{[7]}, T$.

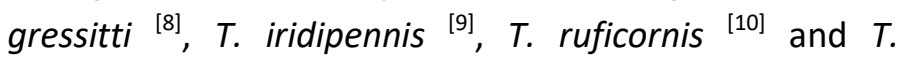
fuscobalteata Cameron ${ }^{[7]}$.

\section{How to cite this article}

Basanna M, Rajanand MC. Study of External Nest Appearances and Foraging Behavior of Tetragonula nr. pagdeni. SSR Inst. Int. J. Life Sci., 2021; 7(6): 2921-2930.

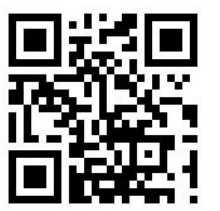

The stingless bees visit the male flowers as well as female flowers ${ }^{[11]}$. The Colonies are perennial and societal structure is also interesting ${ }^{[12]}$. Different stingless bee species nest in various cavities in the trees. A few species live in termite nests. Stingless bees collect several types of material on their foraging flights ${ }^{[2]}$. Their nests are usually not seen easily, but their service as pollinators is appreciated in the scientific community. Honey also possesses medicinal values.

Stingless bees are mainly associated with tropical dry and humid forests, in low and warm lands ${ }^{[13]}$, but the metropolitan cities have made the situation worst by polluting the environment. There are reports of declining populations of honey bees including the stingless bees due to the heavy traffic, which has contributed to decreased air quality. 
Man has been spraying a large number of highly poisonous pesticides in the environment and on crops which removes stingless bees or due to this. The food sources of these tiny creatures get poisoned [14]. The talk is to conserve ecologically relevant animal species whose real role in the future of humankind is immense ${ }^{[15]}$. Natural calamities such as epidemics may end the human population as we are witnessing in this Covid-19 daunted situation everywhere. Similarly, the animals may be deprived of the essential food sources in the future if important insect pollinators of the crops are destructed due to the tremendous nondegradable pesticide use. In this regard, we planned to explore ecobehavioural aspects of $T$. nr. pagdeni, in three regions of Bengaluru. Thus, preliminary information about this stingless bee could be assessed in these surroundings.

\section{MATERIALS AND METHODS}

This study was conducted to elucidate data on the nesting sites, external nest characteristics, foraging behaviour at three selected study areas, pollen sources and identification and determination of the percentage of drone bees of $T \mathrm{nr}$. pagdeni at Bengaluru, Karnataka, India, during the months of summer in the year 2019. The selected three study areas are Campus of University of Agricultural Science (GKVK), Government Science College and DGQA Residential Complex (CQAL campus).

Study area- The study was conducted at three different areas in Bengaluru each distanced $8 \mathrm{~km}$ apart from the other.

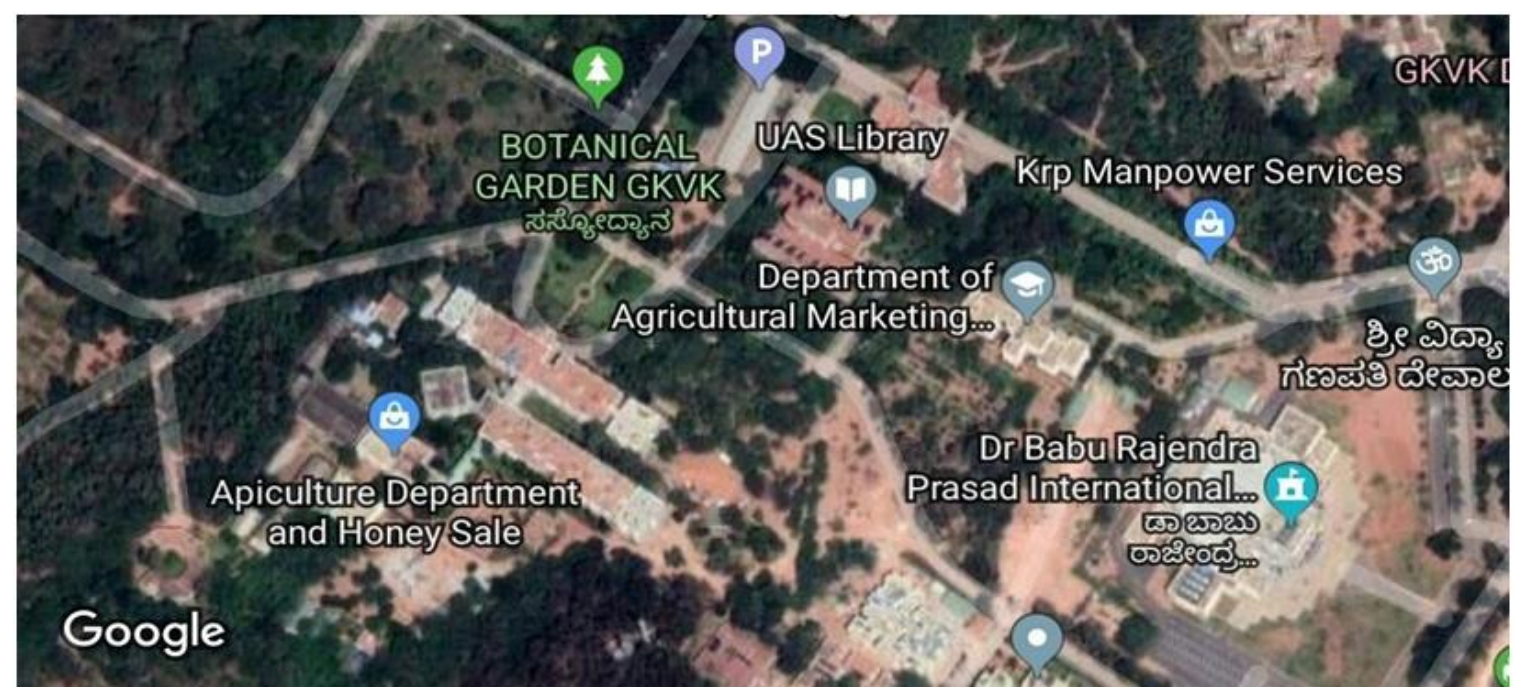

Fig. 1: Satellite view of study area around the Department of Apiculture, University of Agricultural Science (GKVK), Hebbal, Bengaluru (Source: Google maps, Internet)

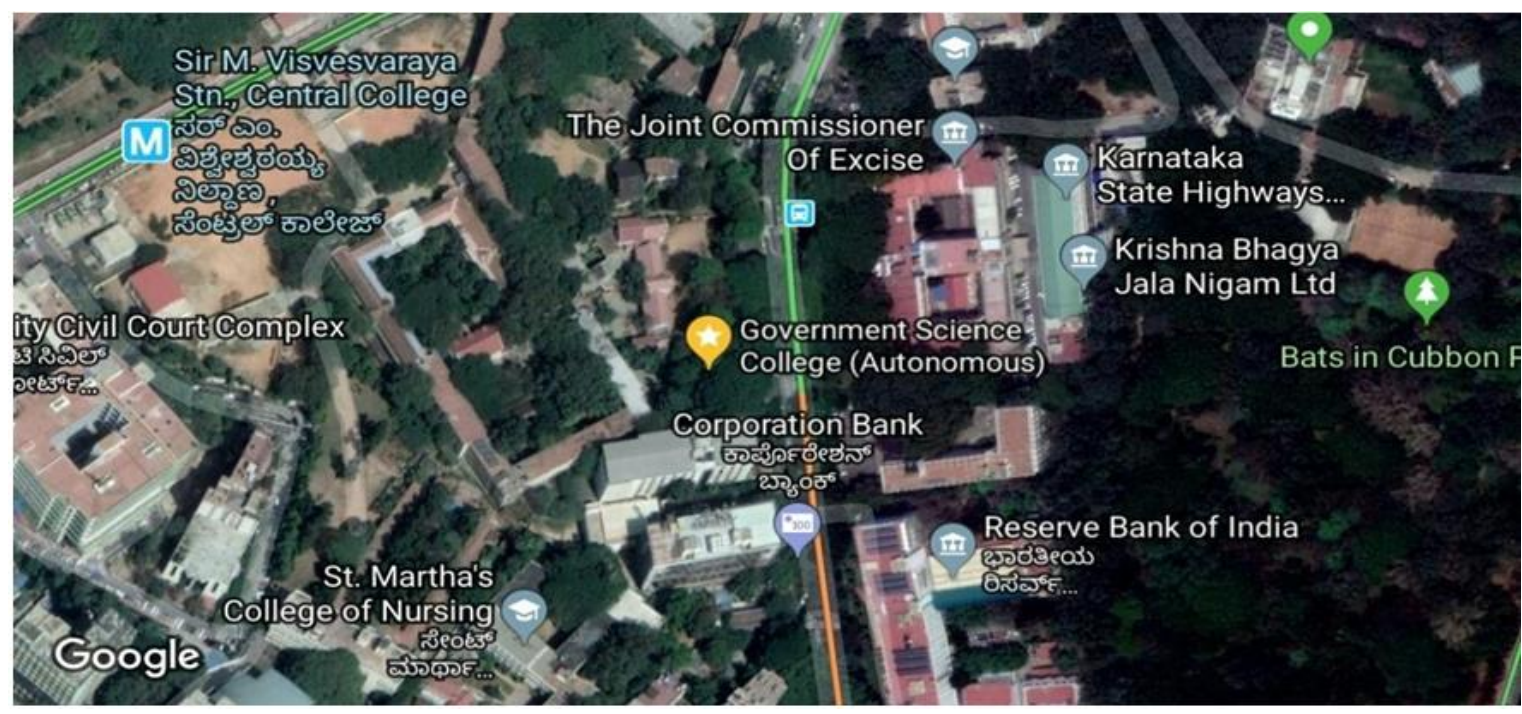

Fig. 2: Satellite view of the study area near Biotechnology department, Government Science College (Autonomous), Nrupathunga road, Bengaluru (Source: Google maps, Internet) 


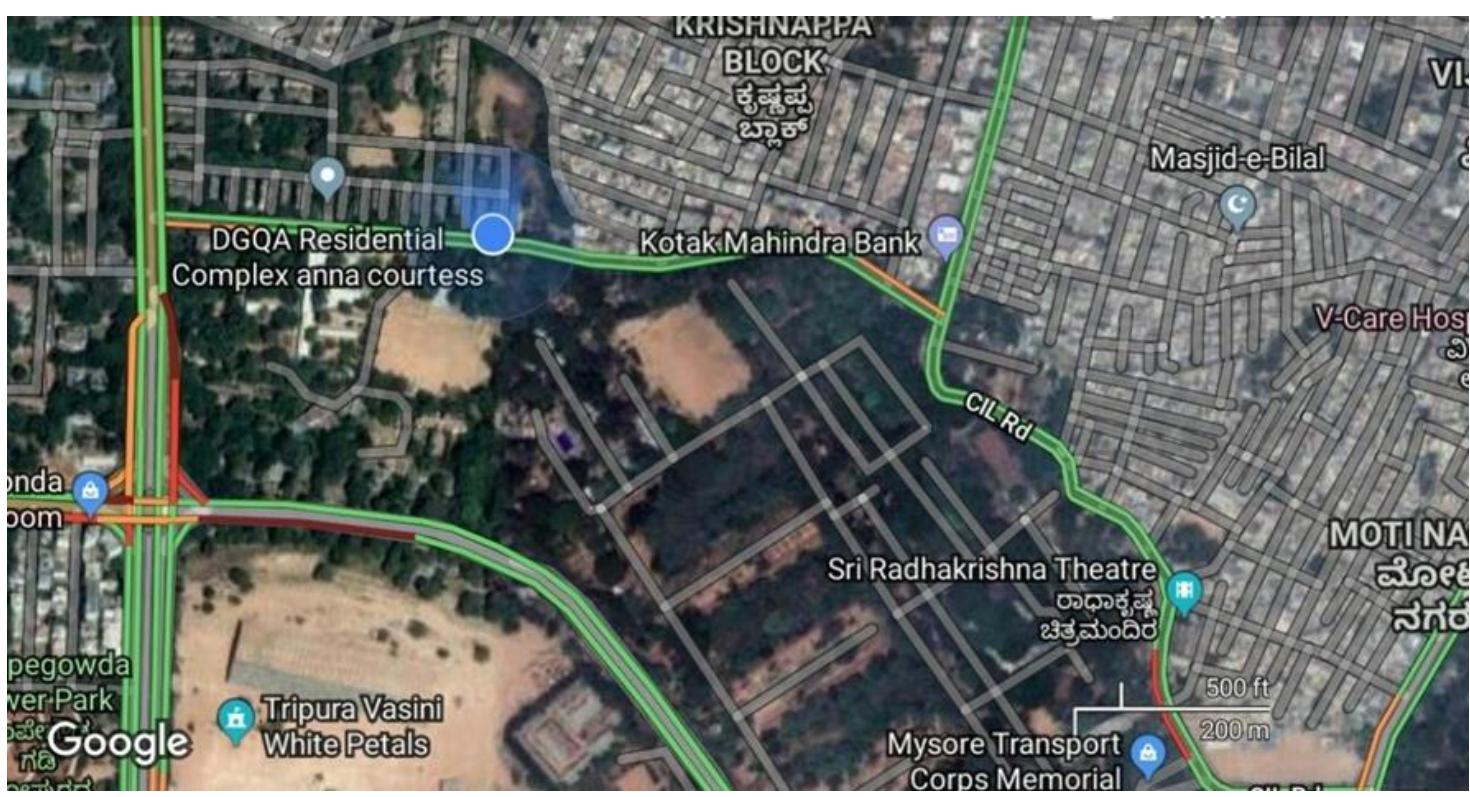

Fig. 3: Satellite view of study area around DGQA Residential Complex, Gunata Vihar, CQAL Campus, J.C. Nagar, Bengaluru (Source: Google maps, Internet)

Nesting sites and external nest structure- The following observations were recorded while studying the nesting sites of colonies of stingless bees found in and around three study areas: Nesting place, height from the ground level $(\mathrm{mm})$, and external nest measurements (length and width of the entrance tube in $\mathrm{mm}$ ). The cavity dimensions were measured using a centimetre-scale and the height from the ground level was measured using a measuring tape (measuring inches, $\mathrm{cm}$ and $\mathrm{ft}$ ).

Foraging behavior of Tetragonula nr. Pagdeni- For this study, five colonies of Tetragonula nr. pagdeni from two study areas were selected (GKVK, Bengaluru and Government Science College, Bengaluru). The foraging activity in terms of the number of outgoing foragers and number of incoming foragers with and without pollen load was recorded at an interval of two hours from 700 to 1700 hours, for five minutes. The pollen grains were subjected to the Standard Acetolysis method of pollen analysis ${ }^{[16]}$ and the identification of pollen was made with the help of the specialist at the University of Agricultural Sciences (GKVK), Bengaluru using reference slide collection.

\section{RESULTS}

Investigations have been carried out on stingless bee Tetragonula nr. pagdeni around Bengaluru. The results are enumerated in this chapter.

Nesting sites and external nest characteristics- Total 28 stingless bee colonies have been studied for nesting sites and external nest characteristics in the selected study sites in Bengaluru. To analyze the nesting habitats of stingless bee Tetragonula nr. pagdeni, 28 colonies were studied (Table 1). Of the 28 stingless bee nests, twenty were found in stone walls at a mean height of $1537.7 \mathrm{~mm}$ from the ground. Five colonies were seen nesting in materials made out of metals at a mean height of $1446.0 \mathrm{~mm}$. Other nesting places were cement walls, PVC pipes and tree cavities where one colony in each of them was found. Among nesting sites, stone walls were found to be the most preferred nesting place or site for Tetragonula nr. pagdeni. At one study area, seven colonies were found to be aggregated in a single stone wall (at Government Science College, Bengaluru).

The entrance of the colony was either made of mud or a waxy dark coloured substance called resin. The most preferred substance used for building the entrance tube was found to be resin. In three colonies nested in metal poles or metal doors, the entrance tube was not distinct. In those colonies which had an entrance tube, the length of the entrance tube of colonies nested in stone walls ranged from $17.52 \mathrm{~mm}$ to $24.18 \mathrm{~mm}$ with a mean length of $20.85 \mathrm{~mm}$ while the width ranged from $8.28 \mathrm{~mm}$ to $7.22 \mathrm{~mm}$ with a mean width of $7.75 \mathrm{~mm}$. Similarly, the length of the entrance tube of colonies nested in metal frames ranged from $1.95 \mathrm{~mm}$ to $9.25 \mathrm{~mm}$ with a mean of $5.6 \mathrm{~mm}$ and the width ranged from $3.27 \mathrm{~mm}$ to $4.73 \mathrm{~mm}$ with a mean of $4.0 \mathrm{~mm}$. The dimensions of the entrance tube of the colonies nested in other sites are presented in Table 1. 
Table 1: Nesting sites of Stingless bee, Tetragonula nr. pagdeni in Bengaluru

\begin{tabular}{ccccc}
\hline \multirow{2}{*}{ Nesting places } & $\begin{array}{c}\text { Number of } \\
\text { colonies observed }\end{array}$ & $\begin{array}{c}\text { Height from the } \\
\text { ground }(\mathbf{m m})\end{array}$ & \multicolumn{2}{c}{ Entrance tube dimensions } \\
\cline { 4 - 5 } Stone wall & 20 & $1537.70 \pm 205.60$ & $7.75 \pm 0.53$ & Length $(\mathbf{m m})$ \\
Metal material & 5 & $1446.00 \pm 228.07$ & $4.00 \pm 0.73$ & $20.85 \pm 3.33$ \\
Cement wall & 1 & 7500.00 & 6.00 & $5.60 \pm 3.65$ \\
PVC pipe & 1 & 2700.00 & 6.00 & 5.00 \\
Tree cavity & 1 & 690.00 & 9.00 & 12.00 \\
\end{tabular}

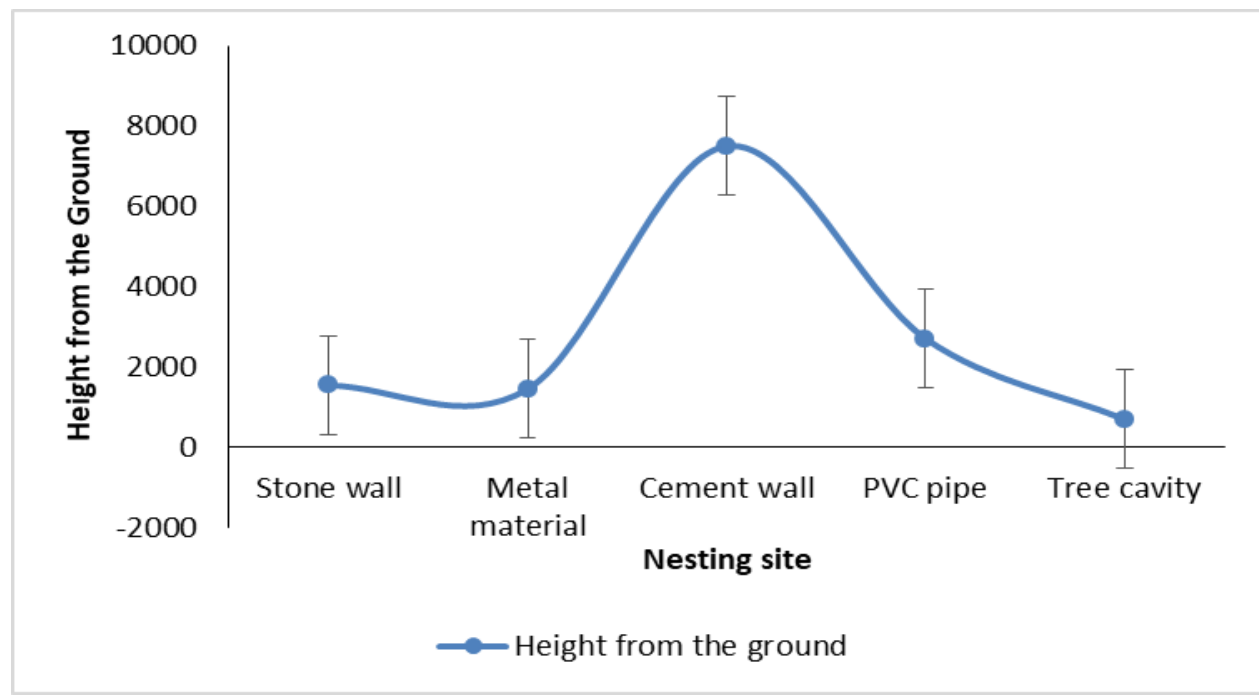

Fig. 2: Nesting elevation of Tetragonula nr. pagdeni colonies at different nesting sites

According to the graph (Nesting sites vs Height from the ground level in millimeters), the highest nesting elevation from the ground was recorded in the colony found in the cement wall $(7500 \mathrm{~mm})$, followed by that of the PVC pipes $(2700 \mathrm{~mm})$. The least nesting elevation from the ground was recorded in that of the tree cavities (690 $\mathrm{mm})$.
Nests in stone wall foraging activity of Tetragonula $\mathrm{nr}$. Pagdeni- Study of foraging behaviour of stingless bee $T$ $\mathrm{nr}$. pagdeni was conducted during summer from March to May at GKVK, Bengaluru and Government Science College, Bengaluru to compare their activity at these different areas being the central aim.

Table 2: Activity of outgoing foragers at GKVK. Bengaluru

\begin{tabular}{|c|c|c|c|c|c|c|c|}
\hline \multirow{2}{*}{ Months/ Hours } & \multicolumn{6}{|c|}{ Mean number of bees/ 5 minutes/ colony } & \multirow{2}{*}{ Mean } \\
\hline & 700 & 900 & 1100 & 1300 & 1500 & 1700 & \\
\hline March & 6.20 & 25.02 & 40.37 & 39.20 & 22.53 & 8.46 & 23.63 \\
\hline April & 5.48 & 13.10 & 34.80 & 27.75 & 20.85 & 8.90 & 18.48 \\
\hline May & 5.40 & 12.70 & 32.17 & 27.79 & 21.13 & 6.63 & 17.64 \\
\hline Mean & 5.70 & 16.94 & 35.78 & 31.58 & 21.50 & 7.99 & \\
\hline
\end{tabular}

Observations were made on the activity of foragers from 0700 hours to 1700 hours at GKVK, Bengaluru. The lowest number of outgoing bees was observed in the morning at 0700 hours with 5.70 bees per 5 mins and evening at 1700 hours with 7.99 bees per 5 mins. 
The activity was at its peak at 1100 hrs with 35.78 bees per 5 mins. While examining the foraging activity month by month, the highest activity was seen in March with
23.63 bees per 5 mins, which declined to 18.48 bees per 5 mins during April which further declined to 17.64 bees per 5 mins during May.

Table 3: Activity of Incoming foragers without pollen load at GKVK, Bengaluru

\begin{tabular}{cccccccc}
\hline \multirow{2}{*}{ Months/ Hours } & \multicolumn{9}{c}{ Mean number of bees/ $\mathbf{5}$ minutes/ colony } & \multirow{2}{*}{ Mean } \\
\cline { 2 - 7 } & $\mathbf{7 0 0}$ & $\mathbf{9 0 0}$ & $\mathbf{1 1 0 0}$ & $\mathbf{1 3 0 0}$ & $\mathbf{1 5 0 0}$ & $\mathbf{1 7 0 0}$ & \\
\hline March & 5.20 & 21.65 & 37.90 & 28.75 & 22.90 & 6.90 & 20.55 \\
\hline April & 3.40 & 10.93 & 24.90 & 17.78 & 16.95 & 9.07 & 13.84 \\
\hline May & 2.19 & 5.82 & 13.17 & 16.18 & 17.04 & 9.43 & 10.64 \\
\hline Mean & 3.59 & 12.80 & 25.32 & 20.90 & 18.96 & 8.46 &
\end{tabular}

The activity of foragers was observed from 0700 hours to 1700 hours at GKVK, Bengaluru. The number of bees without pollen load was the lowest (3.59 bees per 5 mins) at 0700 hours. The significant heightened activity was recorded at 1100 hours ( 25.32 bees per 5 mins). However, at 1700 hours, the activity decreased to the

Table 4: Activity of Incoming foragers with pollen load at GKVK, Bengaluru level of 8.46 bees per 5 mins. When foraging activity was reviewed every month, higher activity was noticed in March with 20.55 bees per 5 mins and a gradual decline in May with the lowest number of bees without pollen load (10.64 bees per 5 mins).

\begin{tabular}{|c|c|c|c|c|c|c|c|}
\hline \multirow{2}{*}{ Months/ Hours } & \multicolumn{6}{|c|}{ Mean number of bees/ 5 minutes/ colony } & \multirow[b]{2}{*}{ Mean } \\
\hline & 700 & 900 & 1100 & 1300 & 1500 & 1700 & \\
\hline March & 2.82 & 5.10 & 11.80 & 11.17 & 5.30 & 2.37 & 6.43 \\
\hline April & 1.82 & 4.72 & 10.70 & 10.31 & 4.48 & 2.47 & 5.75 \\
\hline May & 1.52 & 4.76 & 9.05 & 9.01 & 4.12 & 2.19 & 5.11 \\
\hline Mean & 2.05 & 4.86 & 10.51 & 10.16 & 4.63 & 2.34 & \\
\hline
\end{tabular}

Observations were made on the activity of foragers from 700 hours to 1700 hours at GKVK, Bengaluru (Table 4). The least number of bees with pollen (2.05 bees per 5 mins) was noticed at 0700 hours. The activity gradually increased, peaking at 10.51 bees per 5 minutes at 1100 hours. Subsequently, the foragers gradually decreased to
2.34 bees per 5 mins at 1700 hours by the end of the day. When the activity of foragers was pooled month by month, maximum activity was recorded in March (6.43 bees per 5 mins) which reached a minimum of 5.75 to 5.11 bees per 5 mins from April to May. 


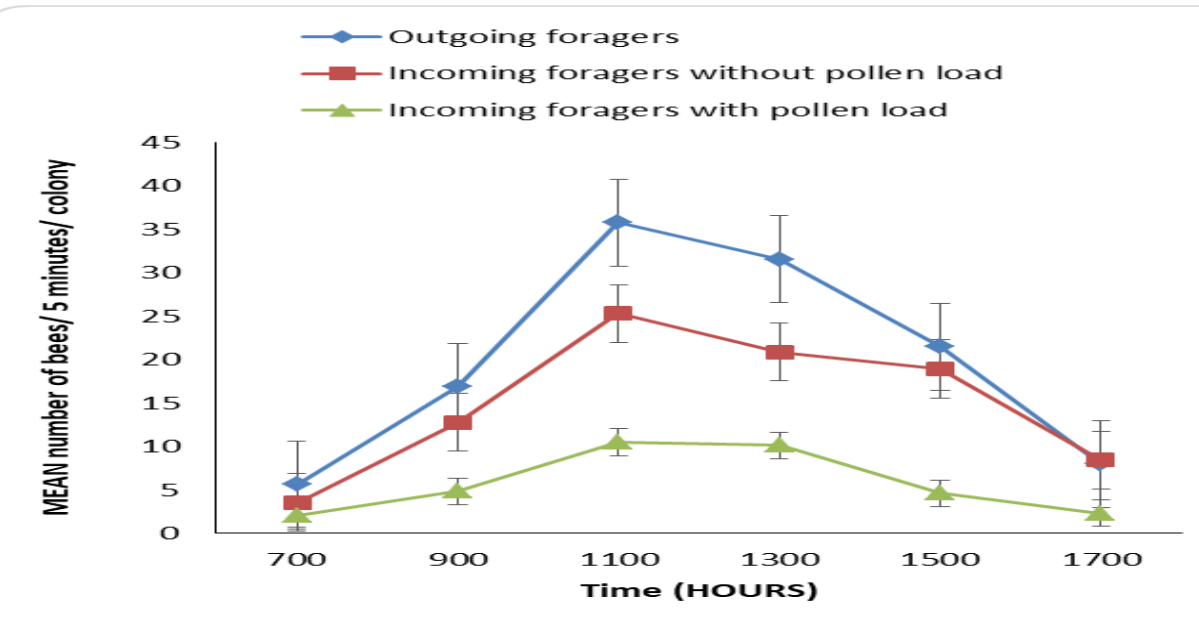

Fig. 5: Foraging activity of T nr. pagdeni during the months of summer at different intervals of time at GKVK, Bengaluru

Table 5: Activity of Outgoing foragers at Government Science College, Bangalore

\begin{tabular}{lllllllll}
\hline \multirow{2}{*}{ Months/ Hours } & \multicolumn{7}{c}{ Mean number of bees/ $\mathbf{5}$ minutes/ colony } & \multirow{2}{*}{ Mean } \\
\cline { 2 - 7 } & $\mathbf{7 0 0}$ & $\mathbf{9 0 0}$ & $\mathbf{1 1 0 0}$ & $\mathbf{1 3 0 0}$ & $\mathbf{1 5 0 0}$ & $\mathbf{1 7 0 0}$ & \\
\hline March & 6.55 & 29.25 & 43.17 & 40.62 & 24.25 & 9.02 & 25.48 \\
\hline April & 6.10 & 13.44 & 35.82 & 28.75 & 21.93 & 9.18 & 19.20 \\
\hline May & 5.97 & 13.23 & 33.16 & 28.76 & 21.70 & 7.30 & 18.35 \\
\hline Mean & 6.21 & 18.64 & 37.38 & 32.71 & 22.63 & 8.50 & \\
\hline
\end{tabular}

The activity of foragers was recorded at Government Science College, Bengaluru, from 0700 hours to 1700 hours. The number of bees leaving their respective nests was the lowest in the morning at 0700 hours with 6.21 bees per 5 mins and in the evening at 1700 hours with 8.50 bees per 5 mins.
The highest activity was observed at 1100 hours (37.38 bees per 5 mins). When the activity of foragers was analyzed month-wise, the highest activity was recorded in March with 25.48 bees per 5 mins, which reduced to 19.20 bees per 5 mins in April which further reduced to 18.35 bees per 5 mins in May.

Table 6: Activity of Incoming foragers without pollen load at Government Science College, Bengaluru

\begin{tabular}{|c|c|c|c|c|c|c|c|}
\hline \multirow[t]{2}{*}{ Months/ Hours } & \multicolumn{6}{|c|}{ Mean number of bees/ 5 minutes/ colony } & \multirow[t]{2}{*}{ Mean } \\
\hline & 0700 & 0900 & 1100 & 1300 & 1500 & 1700 & \\
\hline March & 5.85 & 22.36 & 39.85 & 29.49 & 24.08 & 7.05 & 21.45 \\
\hline April & 4.07 & 11.78 & 26.19 & 19.17 & 17.20 & 9.60 & 14.67 \\
\hline May & 2.75 & 6.15 & 13.68 & 16.56 & 17.88 & 9.83 & 11.14 \\
\hline Mean & 4.22 & 13.43 & 26.57 & 21.74 & 19.72 & 8.83 & \\
\hline
\end{tabular}

The following are the observations made on the activity of foragers at Government Science College, Bengaluru from 0700 to 1700 hours. The least number of incoming bees without pollen load ( 4.22 bees per 5 mins) was recorded at 0700 hrs. A markedly increased activity of 26.57 bees per 5 mins was recorded at 1100 hrs. 
Nevertheless, the activity reduced significantly to the level of 8.83 bees per 5 mins at 1700 hours. When the activity of foragers was studied month-wise, the activity was at its peak in March with 21.45 bees/ 5 mins, which gradually decreased to 11.14 bees per 5 mins during May.

Table 7: Activity of Incoming foragers with pollen load at Government Science College, Bengaluru

\begin{tabular}{lccccccc}
\hline \multirow{2}{*}{ Months/ Hours } & \multicolumn{7}{c}{ Mean number of bees/ $\mathbf{5}$ minutes/ colony } \\
\cline { 2 - 7 } & 0700 & 0900 & 1100 & 1300 & 1500 & 1700 & \multirow{2}{*}{ Mean } \\
\hline March & 2.83 & 5.77 & 13.33 & 13.19 & 6.35 & 3.45 & 7.48 \\
\hline April & 2.25 & 5.37 & 11.10 & 10.68 & 4.70 & 2.45 & 6.09 \\
\hline May & 1.58 & 4.97 & 9.30 & 9.24 & 4.98 & 2.61 & 5.45 \\
\hline Mean & 2.22 & 5.37 & 11.24 & 11.04 & 5.34 & 2.83 & \\
\hline
\end{tabular}

The activity of foragers returning to their respective nests with pollen load was recorded from 0700 hours to 1700 hours at Government Science College, Bengaluru (Table 7). The least number of bees with pollen was recorded ( 2.22 bees per 5 mins) at 0700 hrs. The activity was highest at 1100 hours with 11.24 bees per 5 mins.
However, there was a steep decline in the activity at 1700 hours (2.83 bees per 5 mins).

While examining the activity of foragers month by month, it was found that extreme activity was noticed during March ( 7.48 bees per 5 mins) and the lowest activity ( 5.45 bees per 5 mins) was recorded during May.

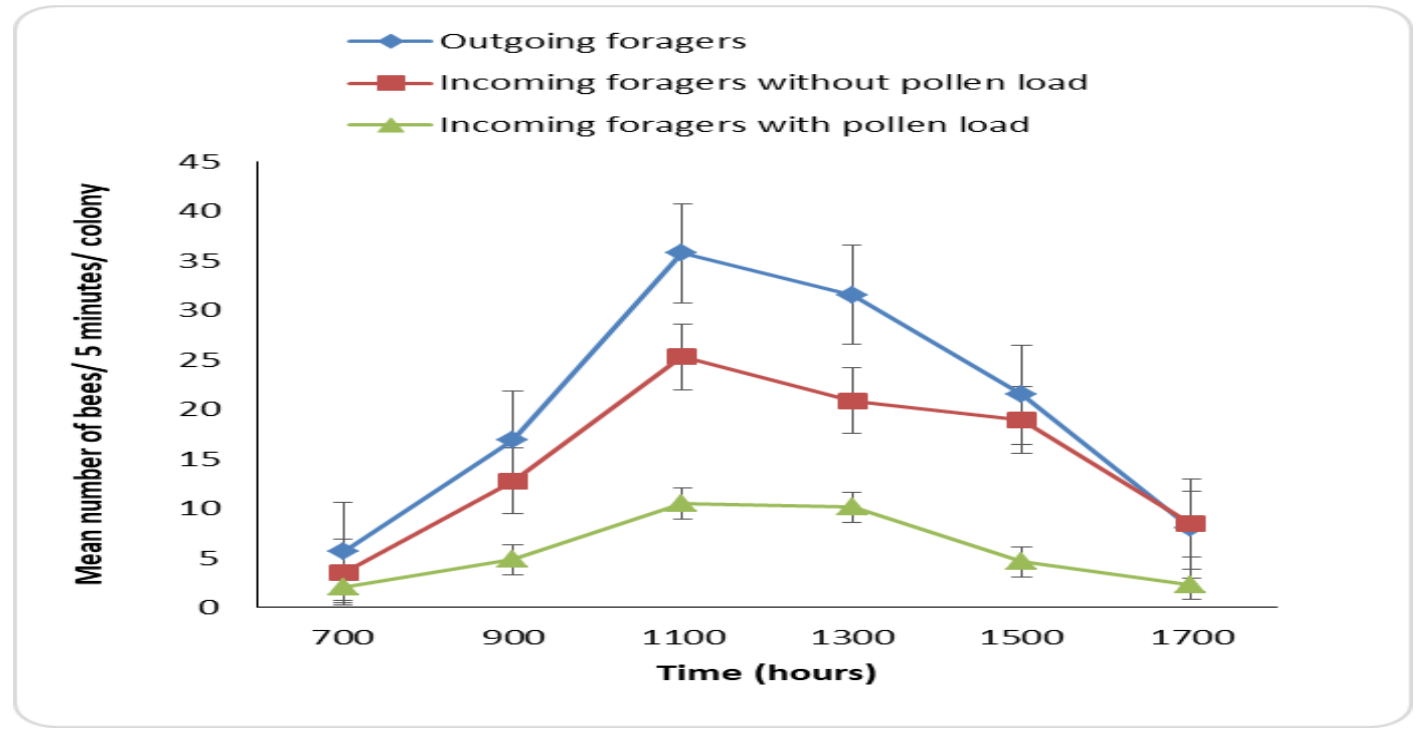

Fig. 6: Foraging activity of $T$. nr. pagdeni during the months of summer at different intervals of timeat Government Science College, Bengaluru

\section{DISCUSSION}

There can be seen a slight increase in the foraging activity of the bees at Government Science College, Bengaluru compared to that of GKVK, Bengaluru. Hence, foraging activity of $T \mathrm{nr}$. pagdeni at Government Science College, Bengaluru is comparatively higher than that of GKVK, Bengaluru. The graph 5 is a plot of number of foragers (X-axis) against the mean of the types of foragers at different months of summer (Y-axis) irrespective of the time of foraging.

Unlike Apis dorsata and Apis florea that construct their nests in open places ${ }^{[17]}$, stingless bees prefer closed structures ${ }^{[18]}$ to construct their nests. The nests of $T$. nr. Pagdeni were found in the cavities of hollow trees, mud walls, cement walls, stone walls, crevices of metal doors and electrical metal pipes in the three areas studied in 
Bengaluru. Similar observations were reported by Gajanan et al. ${ }^{[19]}$; Danaraddi et al. ${ }^{[20]}$ and Vijayakumar et al. ${ }^{[21]}$.

While reporting on the stingless bees of Bhutan, Nidup mentioned that $T$. gressit do not make any nest entrance like L. arcifera; however, it coats the nest tunnel with yellowish substances (likely resin or resin mixed with wax) ${ }^{[22]}$. The mean length, mean width of the entrance tube of nests found in stone walls and tree cavities measured $20.85 \mathrm{~mm}, 7.75 \mathrm{~mm}$ and $23.00 \mathrm{~mm}, 9.00 \mathrm{~mm}$ respectively (Table 1 ). Thangjam et al. ${ }^{\text {[23] reported }}$ similar findings in 2005. At Bankura, the tree nested colonies had a mean entrance tube length of $3.5 \mathrm{~mm}$ ranging from 3-4 $\mathrm{mm}$ and the width of the entrance tube. Each species prefers to build entrance tubes of differing lengths which may depend on the type of nesting site. In Sulawesi (Indonesia), high variations in the type of entrance opening (irregular, round, oval, ellipse, and triangle) and three different brood cells arrangements (semi-cluster, cluster, and semi-comb) for Tetragonula sapiens has been reported. In addition, the nest structure of the endemic stingless bee $W$. incisa, which had a slit longitudinal entrance with lamellate pillar structures in a 2 m cavity of a tree trunk.

Many different types of plant resources are searched to meet the required food resources for a variety of functions to be executed. The pollen supplies protein to the larvae stingless bees differ somewhat from honey bees in those non-floral resources (e.g. resinous materials, fruit juice and carrion also account for a significant proportion of foraging trips ${ }^{[24]}$. Significant variations were observed in the foraging behavior of $T$ nr. pagdeni during different times of the day and the dynamics of activity were similar in the two study areas selected (Table 2 to 7 ). The lowest activity of the foragers was observed during the beginning of the day (700 hours), which gradually rose to attain a peak at 1100 and 1300 hours following which a significant drop in the activity was noticed at 1700 hours(Graph 3 and 4). The exact reason for this behaviour cannot be elucidated. The queen loss changes behaviour and increases longevity in a stingless bee of a particular type [25].

The study was conducted in the months of summer. The highest activity of foragers leaving their nests and returning to their nests with and without pollen load was recorded in March. Two significant peaks of outgoing foragers at 1200 to 1300 hours and 1600 to 1700 hours; and of pollen foragers at 1000 to 1100 hours and 1300 to 1400 hours were recorded respectively by Roopa ${ }^{[26]}$ in Bengaluru. The difference in colony conditions, climatic factors and foraging sources can be the possible reasons for the variations found in the present study.

Also, the foraging activity was found to be comparatively higher at Government Science College, Bengaluru than that found at GKVK, Bengaluru. This can be attributed predominantly to the occurrence of deforestation at a slower rate in GKVK, Bengaluru which can be the most possible reason for comparatively decreased foraging activity of these bees at GKVK, Bengaluru than Government Science College, Bengaluru. Also, at the Government Science College campus the range of foraging areas is less as the pollen and nectar sources are near the nesting site. This can be one of the causes for the increased foraging behaviour of these bees when compared to that of GKVK, Bengaluru. Some new insights were reported about foraging by stingless bees like drinking tear and sweat ${ }^{[27]}$.

\section{CONCLUSIONS}

T. nr. pagdeni nested in the walls of stones and cement, Metal door frames and lamp posts, PVC pipe and tree cavities at Bengaluru. The nest entrance plays a very important role towards nest characters. The nest entrance prevents airstreams but allows slow gas exchange. The nest entrance revealed that bees prefer nest opening of smaller size over the medium and larger opening. The stingless bee identification is now also done through the help of biotechnology- DNA barcoding. The ecologically sustainable, economically viable plants if potted, the stingless bees may try to populate in the diverse habitats even in the urban areas.

In the future, meliponiculture can be planned in the cities by knowing the specific stingless bees abounding in that locality. This can give the added avenue for the income generations as the honey of the stingless bee is in great demand in the market.

\section{CONTRIBUTION OF AUTHORS}

Research concept- Manjunatha $B$

Research design- Manjunatha B and Magdaline Christina $\mathrm{R}$

Supervision- Manjunatha B

Materials- Manjunatha B and Magdaline Christina R 
Data collection- Magdaline Christina R

Data analysis and Interpretation- Magdaline Christina $\mathrm{R}$ Literature search- Magdaline Christina $\mathrm{R}$

Writing article- Manjunatha $B$

Critical review- Manjunatha $B$

Article editing- Manjunatha $B$

Final approval- Manjunatha B

\section{REFERENCES}

[1] Oliveira RC, Contrera FA, Arruda H , Jaffe R, Costa L, et al. Foraging and Drifting Patterns of the Highly Eusocial Neotropical Stingless Bee Melipona fasciculata Assessed by Radio-Frequency Identification tags. Front Ecol Evol., 2021; 517.

[2] Choudhary A, Singh J,ChhunejaPK. Nest Architecture and Nesting Site Preference of Smith in NorthWestern Plains of India. J Apic Sci., 2021; 65 (1): 4959.

[3] Singh HK,Chauhan A. Beekeeping in Nagaland with Stingless Bees: Present and Future. Rassa J Sci Soc., 2020; 2(1): 41-45.

[4] Bui M, Singh HK, Aleminla AO, Chauhan A, Behere GT. Diagnostics of wild stingless bees from northeast India. Indian J Entomol.,2020; 82(2): 337-42.

[5] Thangjam R, Rao S, Viraktamath S, Devarishi Sharma L. First report of drinking tear and sweat by Lisotrigona bees (Apidae: Meliponini) from India. J Apic Res., 2021; pp. 1-3

[6] Prakash AS, Jobiraj T, Bijoy CA. Checklist of bees (Insecta: Hymenoptera: Apoidea) of Kerala. Entomon., 2021; 45(3): 189-200.

[7] Kunal G, Das R, Nagulapalli SL, Layek A, Jha S. Nesting habitat and comb geometry of stingless bee Tetragonula bengalensis Cameron in west Bengal. Ind J Entomol., 2020; 82(3): 445-51.

[8] Chauhan A, Singh HK. Nest architecture of stingless bee Tetragonula gressitti Sakagami from Nagaland India. International Journal of Tropical Insect Scienc., 2021; 22: 1-6

[9] Tej MK, Srinivasan MR ,Vijayakumar K, Natarajan N, Kumar SM. Morphometry Analysis of Stingless Bee Tetragonula iridipennis Smith (1854). Int J Curr Microbiol App Sci., 2017; 6 (10): 2963-70.

[10]Shanas S, Faseeh P. A new subgenus and three new species of stingless bees (Hymenoptera: Apidae: Apinae: Meliponini) from India. Entomon., 2019; 44(1): 33-48.
[11]Krishna S, Somanathan H. Intersexual mimicry and flowering phenology facilitate pollination in a dioecious habitat specialist species, Myristica fatua (Myristicaceae). Plant Ecol., 2018; 219(10): 1247-57.

[12]Bhatta CP, Gonzalez VH, MayesD, Simões M, Smith DR. Nesting biology and niche modelling of Tetragonula iridipennis (Smith) (Hymenoptera: Apidae (Meliponini) in Nepal. J Apic Res., 2019; 58 (4): 501-11.

[13]Reyes-González A, Camou-Guerrero A, Reyes-Salas $O$, Argueta A, Casas A. Diversity, local knowledge and use of stingless bees (Apidae: Meliponini) in the municipality of Nocupétaro, Michoacan, Mexico. J Ethnobiol Ethnomedicine., 2014; 10(1): 1-2.

[14]Cham KO, Nocelli RC, Borges LO, Viana-Silva FE, Tonelli CA, et al. Pesticide exposure assessment paradigm for stingless bees. Environ entomol., 2019; 48(1): 36-48.

[15]Kopnina HN. Half the earth for people (or more)? Addressing ethical questions in conservation. Biol Conserv., 2016; 203: 176-85.

[16]Erdtman G. The acetolysis method: a revised description. Svensk Bot. Tidskr, 1960; 54: 561-64.

[17]Young AM, Kodabalagi S, Brockmann A, Dyer FC. A hard day's night: Patterns in the diurnal and nocturnal foraging behavior of Apis dorsata across lunar cycles and seasons. Plos one., 2021; 16(10): e0258604.

[18]Li YR, Wang ZW, Yu ZR, Corlett RT. Species diversity, morphometrics, and nesting biology of Chinese stingless bees (Hymenoptera, Apidae, Meliponini). Api., 2021; pp. 1-7.

[19]Gajanan S, Mohite GC, Kuberappa GC, Kencharaddi RN. The nest architecture of stingless bee, Trigona iridipennis. Indian Bee J., 2005; 67(1\&2): 36-40.

[20]Danaraddi CS, Manjunath T, Sangamesha H, Biradar SB, Satyareddi SA. Nesting habits and nest structure of stingless bee, Trigona iridipennis Smith at Dharwad, Karnataka. Int J Plant Prot., 2012; 5 (1): 9698.

[21]Vijayakumar K, Jeyaraaj R. Taxonomic notes on Tetragonula pagdeni Schwarz (Apidae: Meliponini) from India. Int J Adv Life Sci., 2020.

[22]Nidup T. Report on the stingless bees of Bhutan (Hymenoptera: Apidae: Meliponini). J Threatened Taxa, 2021; 13(5): 18344-48. 
[23]Thangjam R, Rao S, Viraktamath S, Devarishi SL. First report of drinking tear and sweat by Lisotrigona bees (Apidae: Meliponini) from India. J Api Res., 2021; pp. 1-3.

[24]Sayusti T, Raffiudin R, Kahono S, Nagir T. Stingless bees (Hymenoptera: Apidae) in South and West Sulawesi, Indonesia: morphology, nest structure, and molecular characteristics. J Api Res., 2021; 60(1): 143-56.

[25]Lopes BD, Campbell AJ, Contrera FA. Queen loss changes behavior and increases longevity in a stingless bee. Behavioral Ecol Sociobiol., 2020; 74(3): 1-9.
[26]Roopa CA. Bioecology of stingless bees, Trigona iridipennis Smith, M. Sc. (Ag.) Thesis, University of Agricultural Sciences, GKVK, Bangalore, Karnataka (India), 2002.

[27]Trinkl M, Kaluza BF, Wallace H, Heard TA, Keller A, et al. Floral species richness correlates with changes in the nutritional quality of larval diets in a stingless bee. Insects, 2020; 11(2): 125 . doi: https://doi.org/10.3390/insects11020125. 